\title{
ERIKSON'S YOUNG ADULTHOOD AND EMERGING ADULTHOOD TODAY
}

\author{
Marilyn J. Montgomery \\ Capella University \\ Jeffrey Jensen Arnett \\ Clark University
}

\section{Erikson's Young Adulthood and Emerging Adulthood Today}

In the 60-plus years since Erikson presented his lifespan stage theory in Childhood and Society, not much has changed in the social and cultural context of the early stages. Infants still need to establish trust with someone who will love them and take care of them, incapable as they are of providing for their own needs. Children in early childhood still learn to walk and talk and do some things for themselves. Children in middle childhood still begin to learn to use the tools of their culture, usually by going to school. Adolescence is still a time when identity issues begin to move to the forefront. Building upon successes with these developmental tasks, Erikson saw young adults' psychosocial challenge as "intimacy versus isolation" (Erikson, 1950).

Today Erikson's ideas about this stage are incomplete. Erikson did not specify ages for his stages, but adolescence presumably comprised then, as it does now, the years between reaching puberty to attaining physical and sexual maturity, that is, most of the second decade of life. Then comes young adulthood; and after that, middle adulthood. This means that, in its original formulation, Erikson's "young adulthood" comprised a long stretch of the lifespan, at least a 20 year period, from about age 20-40. Today, it seems that achieving intimacy is only one of the psychosocial challenges that these decades bring.

\section{Young Adulthood-Then and Now}

Seeing intimacy as the key psychosocial issue of young adulthood made sense in 1950. At that time, by age 20 most young people in developed countries were finished with their education (only about 25\% obtained postsecondary education, predominantly men). Young men, at least, had gone to work for an employer they would be likely to have for a long time. By that age, too, young people were married or about to be married, and had become parents or were about to become parents. Hence, they had constructed or were in the process of constructing the structure of their adult lives, in love and work. During their young adulthood, the couple would go on developing their lives in love and work, as their marriage continued and as they raised children together-probably three or four of them, in those days, if they were Americans.

However, in the 60-plus years that have elapsed since Erikson proposed his 
lifespan theory, the early part of what he called "young adulthood" has become unrecognizable from what it was then. "Thirty is the new twenty," as the popular phrase goes, and there is a good reason it has become popular: The structure of a stable adult life is not built at 20 but closer to 30. For most young people, the twenties are no longer a time of settling into the structure of a stable adult life, but a time of maximum disorder, unpredictability, and change. Marriage and parenthood take place in the late twenties or early thirties, more young people pursue education for longer than ever, and job changes are frequent.

Given these changes in how the twenties are experienced in developed countries, there was a need for a new way of thinking about this time of life as a developmental stage or phase. In 2000, Arnett proposed the idea of "emerging adulthood" as a new life stage between adolescence and young adulthood. The idea was widely embraced in the decade that followed; as of July 2011, the article that originally presented the theory had been cited more than 2,000 times, according to googlescholar.com. Clearly there was a widespread sense that a new theory and a new term were required to reflect the changes in development during these years (Arnett, Kloep, Hendry, \& Tanner, 2011).

Arnett (2004) proposed that five features distinguished emerging adulthood as a developmental stage:

- the age of identity explorations

- the age of instability

- the self-focused age

- the age of feeling in-between

- the age of possibilities

To even a casual student of Erikson, it is the first feature that jumps out immediately. What is identity development doing there, when it has long been associated with adolescence? Arguably, in fact, one of Erikson's most influential contributions was his ideas about identity development in adolescence in Identity, Youth, and Crisis (1968). Is not identity achieved by the end of adolescence, as a prerequisite for being ready for the challenges of the life stage that follows?

Perhaps this was true in 1950, but now we live in the next century. The kinds of identity explorations Erikson described, the search for a place in one's society in "love and work" (the famous axiom Erikson attributed to Freud) still begins in adolescence, but it is certainly not resolved or achieved by the end of it. Most of the action in identity development, particularly in role-related identity, now takes place in emerging adulthood, not adolescence. First romantic and sexual relationships may occur in adolescence, but most people are not seriously looking for a life's partner until emerging adulthood. First jobs may occur in adolescence, but it is not until emerging adulthood that people begin a serious search for work they 
plan to be doing for many years to come. Erikson, in fact, saw this change coming, in his idea of the psychosocial moratorium "during which the young adult through free role experimentation may find a niche in some section of his society" (1968, p. 156). Young people following this route were described by Erikson as following a relatively unusual path through this stage of life, but since the time he wrote those words, what was unusual has become normative, as a part of the new life stage of emerging adulthood.

Another observation that should be made about Erikson's ideas on young adulthood is that young adults are extraordinarily focused on developing an intimate relationship, to the neglect or exclusion of the rest of life. Erikson theorized that once individuals consolidated a sense of identity in adolescence, they were ready, in young adulthood, to establish real intimacy in their adult relationships. He saw a sense of identity as a necessary foundation for mutuality in many kinds of adult relationships: "The youth who is not sure of his identity shies away from interpersonal intimacy; but the surer he becomes of himself, the more he seeks it in the form of friendship, combat, leadership, love, and inspiration" (Erikson, 1959, 1980; p. 101).

Attractions and attachments were important in adolescence, he acknowledged, but did not necessarily involve a "true and mutual psychological intimacy" that would be possible in adulthood; to this he famously said, "the condition of a true twoness is that one must first become oneself" (p. 101). Erikson saw the particular psychosocial risk of this stage as isolation, which he described as a tendency to isolate, repudiate, or-if worse comes to worst, destroy- "those forces and people whose essence seems dangerous to one's own" (p. 101).

While these notions highlight relational development as the key advance in this period, it is odd, especially since Erikson specified love, work, and ideology as three important aspects of identity development in adolescence. Love in adolescence becomes intimacy (vs. isolation) in young adulthood, but where did work and ideology go? Ideology is more important for some individuals than for others during this time, but certainly work remains a large part of life in emerging adulthood, young adulthood, and beyond, and it is a puzzling feature of Erikson's theory that it drops out of focus between adolescence and young adulthood.

\section{The Developmental Challenges of Emerging Adults}

Traditionally, and certainly in Erikson's time, the transition from adolescence into adulthood was marked by successfully meeting five challenges: leaving home, completing school, entering the workforce, getting married, and having children. However, entry into adulthood has become more ambiguous as the social timetables that were widely observed a half century ago no longer apply (Arnett, 2004; Settersten, 2011). Emerging adults meet these developmental challenges in a more gradual fashion; increasing numbers will never attain these long-held markers of adulthood as they elect not to marry or have children, cycle back and forth be- 
tween working and obtaining more education or training, and move into or out of the family home to facilitate other goals.

The multiple role involvements that emerging adults now experience-even if transitory and stop-gap in nature - do facilitate continued identity development (Côté, 2006). While Erikson proposed that earlier psychosocial resolutions permit the attainment of subsequent developmental milestones, and that personality developments in identity and intimacy "increase the capacity to do well" (1968, p. 92), he also saw a reciprocal influence between engagement in social roles and psychosocial maturation.

Optimally, emerging adults eventually settle on an answer to the identity question of "who am I?" that includes long-term commitments in work and love. In fact, making commitments that express one's identity is a key to psychological health and well-being (Luyckx, Goossens, \& Soenens, 2006). Those who commit to multiple roles in their 20's have greater identity development in their 40's: a stable personality, behavior that is consistent with internal standards, and independence blended with warmth and compassion (Vandewater, Ostrove, \& Stewart, 1997). Consistent with Erikson's theory, a firm identity which includes both a coherent sense of self and a commitment to particular self-defined and self-defining roles better equips the young person to enter into true mutuality with another (Erikson, 1950; Markstrom \& Kalmanir, 2001).

\section{Value of Erikson's Theory}

We who teach courses on lifespan or adult development to undergraduates or helping professionals have observed that Erikson's theory plays well with those who are themselves emerging adults. They see themselves as involved in the process of exploring and deciding upon the commitments in work and love that they will carry into the future. They resonate with the notion that their previous developmental attainments of (or difficulties with) hope, willpower, purpose, and competence have brought them to their present moment. Further, and especially important for those aspiring to careers in human services or education, they find Erikson's theory useful for providing a developmental explanation of problems ("How does someone get to be like that!?") and for offering a developmental roadmap for interventions designed to help people get their life back on track ("She needs to learn to trust life again, then she'll feel more like trying").

Although Erikson's limitations regarding culture and gender are obvious and have been spoken about by many (e.g., Gilligan, 1987), we find his theory has much to offer. It would be unfair to expect him, any more so than the rest of us, to rise above the cultural horizon of his times (see Sorell \& Montgomery, 2001). Rather, his parsimonious explanation for the development through the lifespan offers a framework upon which more elaborate explanations can be for developed (e.g., Kroger, 2008). Alternatively, and in the case of Arnett's theory of emerging adulthood, contemporary developmental phenomena can be examined and used 
to update Erikson's theory. Arnett and others have advocated extending the approximate age for consolidation of one's identity from adolescence into emerging adulthood, allowing for iterative processes in revising role-related identities and recognizing bidirectionality in the consolidation of a psychological sense of identity with the concurrent development of intimate relationships characterized by deep mutuality (Arnett, 2007; Bosma \& Kunnen, 2001; Montgomery, 2005).

Erikson's theory is useful because it helps us to unify ideas about the lifespan in a general, memorable framework. Perhaps this explains its appeal to each new generation of students. At the same time, his theory implies unspecified processes, making room for the elaboration of notions with a wider range of contemporary applicability such as those offered by Arnett (2000; 2007) and Côté \& Levine (2002).

\section{Supports and Developmental Interventions for Emerging Adults}

College itself is the most notable intervention during this stage; it is experienced by approximately half of the young adults in the United States and Canada. College is renowned for explicitly encouraging identity exploration of many types, including vocational identity, sexual identity, political identity, ethnic and racial identity. Does it indeed facilitate identity development? Certainly, aspects of cognitive development that promote identity exploration and commitment, such as critical and reflective thinking, are fostered by college experiences (Montgomery \& Côté, 2003). College often catalyzes ethnic identity development, probably because of opportunities to access groups and courses of study organized around race. Among minority immigrant young people, college can increase aspirations to do something they like and to be the kind of person they feel they are (Fuligni, 2007, p. 99).

The opportunity to explore options is certainly present in college, but as noted above, being able to make commitments to roles, values, and relationships that express one's identity is also essential. A longitudinal study of identity processes during the first two years of college revealed that emerging adults do explore multiple possibilities in many domains and they also evaluate existing identity commitments. Most students cycled between making commitments and then reevaluating these commitments (Luyckx, Goossens, \& Soenens, 2006). Students who evaluated and became more certain of their commitments were better adjusted academically and socially. However, those who explored multiple possibilities without making commitments were more poorly adjusted-more depressed and higher in drug use (Luyckx et al., 2006). Thus, it may be important for higher education to find ways to provide more assistance to students in choosing and making commitments than have been available to date. For example, rather than leaving academic and career guidance to untrained advisors, colleges could make working closely with a career guidance professional an expected or required aspect of postsecondary education (Herr, Cramer, \& Niles, 2003). Also, youth not attending college can benefit greatly from a mentoring relationship in which they are both supported and challenged as they make life-shaping identity commitments (Tan- 
ner, 2006).

\section{Conclusion}

Erikson's stage theory of the lifespan has been enormously influential in the decades since it was proposed, and like all good theories it has generated a great deal of research. Although he proposed it as a universal theory, from our perspective 60-plus years later, we can see that it was very much a product of its time and place. His ideas about young adulthood in many ways do not fit today's world, perhaps more so than any of his other life stages. Even the greatest theories require modification and change in the long run of science.

One of the most valuable contributions that Erikson's theory made is to show how useful and productive it can be to think of human development in terms of life stages (Arnett et al., 2011). This view, too, has been questioned ever since he proposed his theory, and there are many developmental scientists today who question the value of theories of life stages or even find them to be obstacles to understanding development (Côté \& Bynner, 2008; Hendry \& Kloep, 2007). However, we believe that Erikson has shown that thinking of development in terms of life stages inspires research and promotes deeper insights into human development. His ideas about young adulthood are dated, and it may be that other parts of the theory are in need of revision to fit our times and to articulate more fully than Erikson that cultural context always matters and that there is a limit to what can be considered universal in human development. Nevertheless, Erikson remains a vital part of the scholarly conversation about human development in the 21st century, including the conversation about the third decade of life.

\section{References}

Arnett, J. J. (2000). Emerging adulthood: A theory of development from the late teens through the twenties. American Psychologist, 55, 469-480.

Arnett, J. J. (2004). Emerging adulthood: The winding road from the late teens through the twenties. New York, NY: Oxford University Press.

Arnett, J. J. (2007). Suffering, selfish, slackers? Myths and reality about emerging adults. Journal of Youth and Adolescence, 36, 23-29.

Arnett, J. J., Kloep, M., Hendry, L. A., \& Tanner, J. L. (2011). Debating emerging adulthood: Stage or process? New York, NY: Oxford University Press. 
Bosma, H. A., \& Kunnen, E. S. (2001). Determinants and mechanisms in ego identity development: A review and synthesis. Developmental Review, 21, $39-66$.

Côté, J. E., \& Levine, C. G. (2002). Identity formation, agency, and culture: A social psychological synthesis. Mahwah, NJ: Erlbaum.

Côté, J. E. (2006). Emerging adulthood as an institutionalized moratorium: Risks and benefits to identity formation. In J. J. Arnett \& J. L. Tanner (Eds.), Emerging adults in America: Coming of age in the 21st century. Washington, DC: American Psychological Association.

Côté, J. E., \& Bynner, J. M. (2008). Changes in the transition to adulthood in the UK and Canada: The role of structure and agency in emerging adulthood. Journal of Youth Studies, 11(3), 251-268.

Erikson, E. H. (1950). The growth and crises of the healthy personality. In M. J. E. Senn (Ed.), Symposium on the Healthy Personality, Supplement II; Problems of Infancy and Childhood, Transactions of Fourth Conference. New York, NY: Josiah Macy Jr. Foundation.

Erikson, E. H. (1968). Identity, youth, and crisis. New York, NY: W. W. Norton.

Erikson, E. H. (1959; 1980). Identity and the life cycle. New York, NY: W. W. Norton.

Fuligni. (2007). Family obligation, college enrollment, and emerging adulthood in Asian and Latin American families. Child Development Perspectives, 1, 96-100.

Gilligan, C. (1987). Woman's place in man's life cycle. In S. G. Harding (Ed.), Feminism and methodology: Social science issues. Bloomington, IN: Indiana University Press.

Hendry, L., \& Kleop, M. (2007). Conceptualizing emerging adulthood: Inspecting the emperor's new clothes? Child Development Perspectives, 1(2), 74-79.

Herr, E., Cramer, S., \& Niles, S. (2003). Career guidance and counseling through the lifespan: A systematic approach (6th ed.). Columbus, OH: Allyn \& Bacon.

Kroger, J. (2008). Identity development: Adolescence through adulthood (2nd ed.). Thousand Oaks, CA: Sage. 
Luyckx, K., Goossens, L., \& Soenens, B. (2006). A developmental contextual perspective on identity construction in emerging adulthood: Change dynamics in commitment formation and commitment evaluation. Developmental Psychology, 42(2), 366-380.

Markstrom, C. A., \& Kalmanir, H. M. (2001). Linkages between the psychosocial stages of identity and intimacy and the ego strength of fidelity and love. Identity, 1, 179-196.

Montgomery, M. J. (2005). Psychosocial intimacy and identity: From early adolescence to emerging adulthood. Journal of Adolescent Research, 20, 346-374.

Montgomery, M. J., \& Côté, J. E. (2003). The transition to college: Adjustment, development, and outcomes. In G. R. Adams \& M. Berzonsky (Eds.), The Blackwell handbook of adolescence (pp. 179-194). Oxford, UK: Blackwell.

Sorell, G. T., \& Montgomery, M. J. (2001). Feminist perspectives on Erikson 's theory: Their relevance for contemporary identity development research. Identity, 1, 97-128.

Settersten, R. A. (2011). Becoming Adult: Meanings and markers for young americans. In M. C. Waters, P. J. Carr, M. J. Kefalas, \& J. Holdaway (Eds.), Coming of age in America: The transition to adulthood in the twenty-first century.

Tanner, J. L. (2006). Recentering during emerging adulthood: A critical turning point in life span development. J. J. Arnett \& J. L. Tanner (Eds.), Emerging adults in America: Coming of age in the 21st century (pp. 21-55). Washington, DC: American Psychological Association.

Vandewater, E. A., Ostrove, J. M., \& Stewart, A. J. (1997). Predicting women's well-being in midlife: The importance of personality development and social role involvement. Journal of Personality and Social Psychology, 72, 1147-1160. 